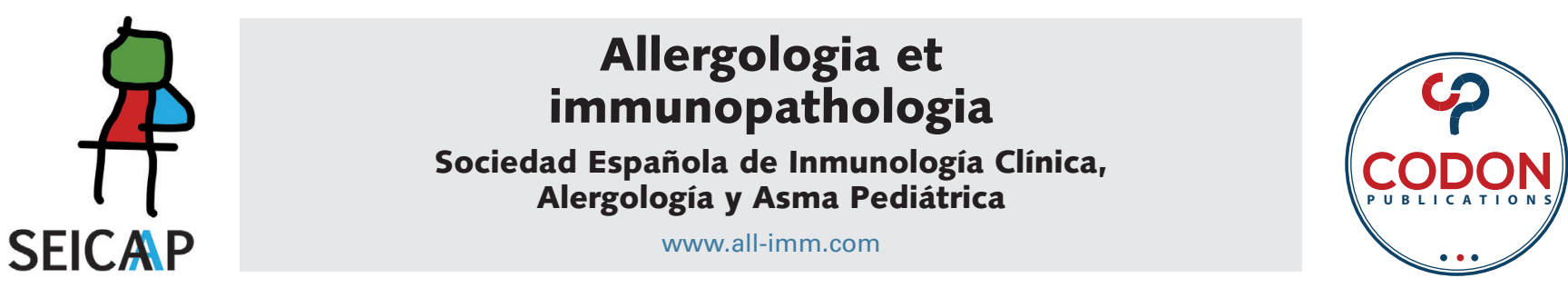

\title{
Mosquito hypersensitivity may be associated with atopic background in children
}

\author{
Süleyman Tolga Yavuz ${ }^{\mathrm{a} *}$, Onur Akin ${ }^{\mathrm{b}}, \mathrm{Ozan}_{\mathrm{K}} \mathrm{Koc}^{\mathrm{b}}$, Ali Güngör ${ }^{\mathrm{b}}$, Ahmet Bolat ${ }^{\mathrm{b}}$, Mustafa Gülec $^{\mathrm{c}}$
}

${ }^{a}$ Department of Pediatric Allergy, Children's Hospital, University of Bonn, Bonn, Germany

${ }^{b}$ Department of Pediatrics, Gülhane Training and Research Hospital, Ankara, Turkey

'Department of Allergy and Clinical Immunology, Gülhane Training and Research Hospital, Ankara, Turkey

Received 23 June 2021; Accepted 2 September 2021

Available online 2 November 2021

\section{KEYWORDS}

children;

large local reaction;

mosquito allergy;

mosquito bite;

unusual reaction

\begin{abstract}
Background: Many children encounter unusual or "exaggerated" reactions such as large local, atypical or systemic reactions after mosquito bites.

Objective: The aim of this study was to document the clinical features of children with mosquito allergy and investigate the possible associations between demographic features and type of reactions in this population.

Methods: Children with large local or unusual reactions after mosquito bites who attended to our outpatient pediatric allergy department were enrolled in the study along with control subjects.

Results: A total of 180 children ( 94 with mosquito allergy and 86 age and sex-matched control subjects) with a median age of 6.8 years (IQR 5.5-9.3) were enrolled. Atopy $(35.1 \%$ vs. $11.6 \%$, $\mathrm{p}<0.001)$ and grass pollen sensitization $(28.7 \%$ vs. $8.1 \%, p<0.001)$ were significantly more frequent in children with mosquito allergy. Skin prick test with mosquito allergen was positive in only 6 children $(6,4 \%)$. Grass pollen sensitization was most common in children $(28.7 \%)$ followed by sensitization to house dust mite (9.6\%). 30 children (31.9\%) had an accompanying atopic disease such as allergic rhinitis, asthma or atopic dermatitis. Bullae were significantly more frequent in children with asthma $(41.7 \%$ vs.15.9, $\mathrm{p}=0.034)$. The median duration of symptoms after onset were significantly longer in patients with ecchymosis, with immediate wheals and in children whose symptoms start in 20 min to 4 hours after mosquito bites.

Conclusion: There is an association between unusual, large local or exaggerated reactions after mosquito bites and allergic diseases in children. The severity of reactions increases with age and particularly in children with atopic background.
\end{abstract}

(c) 2021 Codon Publications. Published by Codon Publications.

*Corresponding author: Süleyman Tolga Yavuz, MD, Department of Pediatric Allergy, Children's Hospital, University of Bonn, Bonn, Germany. Email address: styavuz@yahoo.com 


\section{Introduction}

Mosquito bites cause typical local cutaneous reactions in children and adults. Although these reactions decrease the quality of life in patients, the symptoms resolve in several days without any systemic or severe symptoms in majority of the population. ${ }^{1}$ However, there are patients who encounter unusual or "exaggerated" reactions such as large local, atypical, or systemic reactions after mosquito bites. Even though the immune mechanisms associated with the reaction type and severity are not completely found out, such reactions are defined as mosquito hypersensitivity, and due to the limited availability of the in vivo and in vitro diagnostic methods, the diagnosis is primarily made with the help of clinical history and physical examination findings. ${ }^{2}$

Several cross-sectional and longitudinal studies have been performed to determine the natural course of these reactions. It has been suggested that natural desensitization may occur in adolescence, and young children may be at increased risk of having severe reactions to mosquito bites. ${ }^{3,4}$ However, data regarding the demographic features of children with hypersensitivity to mosquito bites are limited.

The aim of this study was to document the characteristics of children who encounter unusual, severe, or "exaggerated" reactions after mosquito bites and investigate the possible associations between demographic features and clinical reactions in this population.

\section{Materials and Methods}

\section{Study design, setting, and participants}

Children aged 2-17 years, who had admitted to the Pediatric Allergy and Asthma Unit of Gulhane School of Medicine with unusual or "exaggerated" reactions after mosquito bites between 2013 and 2018, were consecutively enrolled in the study along with age- and sex-matched control subjects, who tolerated several mosquito bites without any systemic, unusual, or large local reaction. Children in the control group had no history of physician-diagnosed allergic diseases, and they were admitted to our outpatient department for routine medical checkup.

The patient group consisted of children with mosquito hypersensitivity. "Mosquito hypersensitivity" is defined as large local reactions to mosquito bites, which consist of itchy, red, warm swellings appearing within minutes of the bites, and atypical reactions such as itchy papules, ecchymosis, vesiculated, blistering, and bullous reactions, appearing in $6 \mathrm{~h}$ after the bites and persisting for days or weeks. ${ }^{5}$ Demographic data, history of reaction after mosquito bite (onset of the reaction, reaction type), and personal and familial history of other atopic diseases were recorded. Physical examination, morphology, and other clinical manifestations of skin lesions were recorded. The skin reaction features of the children at the time of enrollment were classified into five stages due to the lifetime course of the process of sensitization and desensitization, as previously reported: (a) Stage 1, the bites cause no or little reaction (wheal $<4 \mathrm{~mm}$, erythema $<4 \mathrm{~mm}$, or papule $<3 \mathrm{~mm}$ ); (b) Stage 2, delayed reaction only (erythematous papules $>4 \mathrm{~mm}$ develop 3-4 $\mathrm{h}$ after bite and with a peak at 24-36 h); (c) Stage 3, immediate reaction followed by delayed reaction (wheal $>4 \mathrm{~mm}$ develops a peak $\leq 20$ min after bite); (d) Stage 4, immediate reaction only; and (e) Stage 5, those with repeated bites who eventually lost reactions. $^{2}$

Asthma was defined as current symptoms (wheeze and cough) and positive bronchodilator responsiveness (improvement of $\mathrm{FEV}_{1}$ by $12 \%$ or more following administration of $200 \mathrm{mcg}$ salbutamol), and/or a positive response to a trial of therapy with inhaled or oral corticosteroids. ${ }^{6}$ Allergic rhinitis was defined by the presence of rhinitis symptoms (rhinorrhea, nasal obstruction, nasal itching, and sneezing), which are reversible spontaneously or with treatment in children with aeroallergen sensitization in the skin prick test. ${ }^{7}$ Atopic dermatitis was defined as the presence of pruritus and a relapsing eczematous rash typically found over flexor surfaces. ${ }^{8}$

The study was approved by the Institutional Review Board of Gulhane School of Medicine, and written informed consent was obtained from parents.

\section{Study measurements}

Skin tests. All children underwent skin prick testing (SPT) to mosquito allergen with commercial extract of Aedes communis (Stallergenes, Anthony, France), along with common aeroallergens for our region, ${ }^{9}$ including house dust mites (Dermatophagoides pteronyssinus and Dermatophagoides farinae), grass pollen mix (Phleum pratense, Poa pratensis, Dactylis glomerata, Lolium perenne, Festuca pratensis, and Avena eliator), weed pollen mix (Artemisia, Urtica, Taraxacum, Plantago), tree pollen mix (Alnus glutinosa, Corylus avellane, Populus alba, Ulmus minor, Betula alba), molds (Alternaria, Cladosporium, Penicillium, and Aspergillus), and animal dander (cats and dogs). Histamine (10 $\mathrm{mg} / \mathrm{ml}$ of histamine phosphate) and $0.9 \%$ saline were used as positive and negative controls, respectively. Wheal $3 \mathrm{~mm}$ greater than negative control was considered a positive reaction.

Blood eosinophil counts and serum total IgE levels. Blood eosinophil counts were determined from Coulter Counter (Beckman Coulter, Fullerton, CA, USA) leucocyte measurements. Total serum IgE level was measured using ImmunoCAP (Phadia AB, Uppsala, Sweden).

\section{Statistical analysis}

Analyses were performed using SPSS Statistics v21.0 (IBM, Chicago, IL, USA). Not normally distributed continuous data were expressed as median and interquartile ranges (IQR). Group comparisons were carried out using Mann-Whitney U-test or Kruskal-Wallis test as appropriate for the continuous, and chi-square test or Fisher's test for categorical variables. The correlation coefficients between clinical manifestations and other clinical variables were determined using Spearman's rank correlation or Pearson's coefficient. $\mathrm{P}$ level $<0.05$ was considered significant. 


\section{Results}

\section{Descriptive statistics}

A total of 180 children (94 with mosquito hypersensitivity and 86 healthy controls) with a median age of 6.8 years (IQR 5.5-9.3) were enrolled. Characteristics of the study groups are presented in Table 1. There were no significant differences between the children with mosquito hypersensitivity and healthy controls in terms of SPT positivity to mosquito allergen. Atopy $(35.1 \%$ vs $11.6 \%, \mathrm{P}<0.001)$ and grass pollen sensitization $(28.7 \%$ vs $8.1 \%, \mathrm{P}<0.001)$ were significantly more frequent in children with unusual reactions and they had significantly higher eosinophil counts and total IgE levels compared to healthy controls.

\section{Clinical features of children with mosquito hypersensitivity}

Clinical characteristics of the children in this group are presented in Table 2. The median age of onset of reactions to mosquito bites was 3.3 years (IQR 2.0-5.6). The median duration of symptoms after onset was 2.7 years (IQR 1.24.3). Eleven children (11.7\%) had a positive family history of mosquito allergy. SPT with mosquito allergen was positive in only six children (4\%) with mosquito hypersensitivity. About $35.1 \%$ of patients had sensitization to at least one aeroallergen. Grass pollen sensitization was most common in children $(28.7 \%)$, followed by sensitization to house dust mite (9.6\%). Thirty children (31.9\%) had an accompanying atopic disease such as allergic rhinitis, asthma, or atopic dermatitis. Four children (4.3\%) had symptoms of Skeeter

Table 1 Demographic and laboratory characteristics of the study groups $(n=180)$.

\begin{tabular}{lccc}
\hline & $\begin{array}{c}\text { Mosquito } \\
\text { hypersensitivity } \\
(\mathrm{n}=94)\end{array}$ & $\begin{array}{c}\text { Control } \\
\text { group } \\
(\mathrm{n}=86)\end{array}$ & $\mathrm{P}$ \\
\hline Age, years & $6.6(4.4-9.7)$ & $6.9(6.1-8.7)$ & 0.36 \\
Male sex & 53.2 & 46.5 & 0.37 \\
SPT positivity to & 6.4 & 1.2 & 0.12 \\
$\quad$ mosquito & & & \\
Atopy & 35.1 & 11.6 & $<0.001$ \\
$\quad$ Grass pollens & 28.7 & 8.1 & $<0.001$ \\
House dust mites & 9.6 & 4.7 & 0.20 \\
Cat dander & 2.1 & 0 & 0.50 \\
Mold & 5.3 & 1.2 & 0.21 \\
Dog dander & 0 & 0 & $\mathrm{NA}$ \\
Tree pollens & 2.1 & 1.2 & 0.61 \\
$\quad$ Weed pollens & 1.1 & 1.2 & 0.95 \\
Eosinophils, \% & $2.9(1.6-4.3)$ & $1.8(1.3-2.5)$ & 0.001 \\
Eosinophils $(/ \mathrm{ml})$ & $195(140-300)$ & $135(80-200)$ & $<0.001$ \\
Total IgE (IU/ml) & $62(22-153)$ & $19(8-69)$ & $<0.001$ \\
\hline Data are presented & &
\end{tabular}

Data are presented as percentage or median (interquartile range). Bold values denote statistical significance at the $\mathrm{p}<0.05$ level.

SPT: Skin prick test
Table 2 Clinical characteristics of the children with mosquito hypersensitivity $(n=94)$.

\begin{tabular}{lc}
\hline Age, years & $6.6(4.4-9.7)$ \\
Male sex & 53.2 \\
Age at symptoms start, years & $3.3(2.0-5.6)$ \\
Duration of symptoms after onset, years & $2.7(1.2-4.3)$ \\
Family history of mosquito hypersensitivity & 11.7 \\
Family history of allergic diseases & 25.1 \\
Accompanying allergic diseases & 31.9 \\
$\quad$ Allergic rhinitis & 22.3 \\
Asthma & 12.8 \\
Atopic dermatitis & 5.3 \\
Skeeter syndrome & 4.3 \\
\hline Data are presented as percentage or median (interquartile \\
range).
\end{tabular}

syndrome with large cellulitis-like local inflammatory reaction and fever.

\section{Clinical manifestations of children with mosquito hypersensitivity}

Table 3 shows the clinical manifestations of the patients and the comparison of symptom duration according to the features of the reactions. Most children in our study were in Stage 2 (72.8\%) followed by children in Stage 3 (26.1\%). There was only one child $(1.1 \%)$ in Stage 4 . There were no children in Stage 1 or Stage 5 . The most common skin lesion was erythematous papule $(92.6 \%)$. Generalized urticaria was detected only in $4.3 \%$ of the children. In $76.1 \%$ of children, skin reactions developed later than $4 \mathrm{~h}$ after mosquito bite. The lesions recovered within seven days in twothird of the children (61.7\%). The diameter of the lesions was larger than $10 \mathrm{~cm}$ in $9.4 \%$ of the children. Ecchymosis was significantly more frequent in children with reactions larger than $10 \mathrm{~cm}$ compared to children with smaller lesions (47.1\% vs $17.3 \%, P=0.021$ ) and in boys compared to girls (32.0\% vs $13.6 \%, P=0.036)$. Bullae were significantly more frequent in children with asthma $(41.7 \%$ vs $15.9 \%, \mathrm{P}=0.034)$.

\section{Correlation between the characteristics of symptoms and clinical features}

There were no significant correlations between age, age at onset of symptoms, gender, duration of symptoms, time to recovery of the lesions, stage of the bite reaction, and skin test positivity to mosquito. The median duration of symptoms after onset was significantly longer in patients with ecchymosis (3.8 years [IQR 2.4-4.8] vs 2.4 years [IQR 0.8 3.8]; $\mathrm{P}=0.024)$ and immediate wheals (3.8 years [IQR 2.5-5.1] vs 2.5 years [IQR 0.9-4.1]; $\mathrm{P}=0.047$ ). The median duration of symptoms was also significantly longer in children whose symptoms started in 20 min to $4 \mathrm{~h}$ when compared with children whose symptoms developed later than $4 \mathrm{~h}$ after mosquito bites (3.5 years [IQR 1.6-4.6] vs 2.0 years [IQR 0.7-3.7]; $\mathrm{P}=0.027$ ). There were no significant correlations between skin test positivity to mosquito and clinical features. 
Table 3 Clinical manifestations of the children with mosquito hypersensitivity $(n=94)$.

\begin{tabular}{|c|c|c|c|}
\hline Features of skin lesions & & $\begin{array}{l}\text { Duration of } \\
\text { symptoms } \\
\text { (years) }\end{array}$ & $\mathrm{P}$ \\
\hline \multicolumn{4}{|l|}{ Stage of reaction } \\
\hline Stage 1 & 0 & & 0.39 \\
\hline Stage 2 & 72.8 & $2.5(0.9-4.3)$ & \\
\hline Stage 3 & 26.1 & $3.2(1.3-4.5)$ & \\
\hline Stage 4 & 1.1 & $3.5(3.5-3.5)$ & \\
\hline Stage 5 & 0 & & \\
\hline Erythematous papule & & & 0.22 \\
\hline Yes & 92.6 & $2.8(1.2-4.6)$ & \\
\hline No & 7.4 & $2.0(1.1-2.9)$ & \\
\hline Vesicle & & & 0.25 \\
\hline Yes & 43.6 & $3.0(1.6-4.5)$ & \\
\hline No & 56.4 & $2.4(0.9-4.2)$ & \\
\hline Ecchymosis & & & 0.024 \\
\hline Yes & 23.4 & $3.8(2.4-4.8)$ & \\
\hline No & 76.6 & $2.4(0.8-3.8)$ & \\
\hline Immediate wheal & & & 0.047 \\
\hline Yes & 16.3 & $3.8(2.5-5.1)$ & \\
\hline No & 83.7 & $2.5(0.9-4.1)$ & \\
\hline Bullae & & & 0.29 \\
\hline Yes & 19.1 & $2.5(0.6-4.0)$ & \\
\hline No & 81.9 & $2.8(1.2-4.6)$ & \\
\hline Generalized urticaria & & & 0.65 \\
\hline Yes & 4.3 & $3.5(1.8-3.9)$ & \\
\hline No & 95.7 & $2.6(1.1-4.5)$ & \\
\hline Onset of reaction after bite & & & 0.027 \\
\hline $20 \min -4 h$ & 23.9 & $3.5(1.6-4.6)$ & \\
\hline$>4 \mathrm{~h}$ & 76.1 & $2.0(0.7-3.7)$ & \\
\hline Time of resolving & & & 0.68 \\
\hline 1-6 days & 61.7 & $2.5(1.2-4.1)$ & \\
\hline$>7$ days & 38.3 & $2.8(1.1-4.7)$ & \\
\hline
\end{tabular}

Data are presented as percentage or median (interquartile range). Bold values denote statistical significance at the $\mathrm{p}<0.05$ level.

\section{Discussion}

The results of our study, which were conducted in a group of children who encounter unusual or "exaggerated" reactions after mosquito bites, revealed the high frequency of aeroallergen sensitization along with atopic diseases in the study population. The diagnostic role of the mosquito commercial extract was very limited in this group of children. Our results also found out several associations between the duration of symptoms and the features of skin reactions after mosquito bites in children with mosquito hypersensitivity.

One-third of the children had at least one allergic disease such as allergic rhinitis, asthma, or atopic dermatitis. When we tried to compare our findings with previous studies, we noticed a lack of studies that were performed in children with allergic reactions after mosquito bites. The study by Manuyakorn et al..$^{10}$ is the only previous childhood study that presents the demographic and clinical features of children who encounter allergic reactions after mosquito bites. They have reported data from 50 Thai children, and although they did not perform SPT with aeroallergens, the frequency of accompanying atopic diseases was $76 \%$ in this group of children. However, the details and the definitions of the atopic diseases were not described. In the study by Kulthanan et al. ${ }^{11}$ which reported the clinical features of 70 adults with mosquito allergy, $58.6 \%$ of the patients had a personal history of atopy. Nearly half of the patients had allergic rhinitis, which was comparable to our results. Due to the design of our study, we have included only healthy children without any physician-diagnosed allergic disease in the control group. Therefore, a clear statement regarding the increased prevalence of allergic rhinitis in children with mosquito allergy cannot be extracted from our results. Nevertheless, the prevalence of physiciandiagnosed allergic rhinitis in children varies between $8.1 \%$ and $13.4 \%$ according to the results of previous childhood studies conducted in Turkey. ${ }^{12,13}$ In consistent with the previous studies, it can be speculated that large local reactions and/or unusual reactions after mosquito bites are more encountered in patients with allergic diseases. Further studies including children with allergic diseases and without reactions after mosquito bites are needed to support this hypothesis.

The prevalence of atopy, particularly grass pollen allergy, was significantly more frequent in our cohort of children with unusual reactions after mosquito bites when compared with healthy children without any reactions. We have found a positive relationship between grass pollen allergy and mosquito reactivity in SPT.

In the study by Kulthanan et al., house dust mite was the most common allergen in SPT in patients with mosquito allergy. ${ }^{11}$ Scala et al. ${ }^{14}$ have performed a multicenter study in 205 individuals who reported large local reactions after mosquito bites and found significant relationships in SPT reactivity between mosquito (A. communis), house dust mite (D. pteronyssinus), cockroach (Blattella germanica), and bee (Apis mellifera) allergens. They have concluded that in individuals with severe local reactions following mosquito bites, the immune response to mosquito allergens is associated with both species-specific and cross-reactive bee venom components, suggesting "bee-mosquito syndrome." In our cohort, there was no child with bee or wasp allergy. However, 32 children (34\%) had a history of bee and/or wasp sting.

Bemanian et al. have investigated the prevalence of insect aeroallergens in their cohort of 86 patients ( 31 children and 55 adults) with allergic rhinitis..$^{15}$ Approximately one-third of the patients were sensitized to mosquito allergen in SPT. However, there are no data available about the reactions after mosquito bites. Cantillo et al. ${ }^{16}$ have evaluated the cross-reactivity between mosquito allergens (Aedes aegypti) and other arthropods in serum samples of 34 patients with asthma and/or allergic rhinitis and reported a cross-reactivity between $A$. aegypti and mites, shrimp, and cockroach.

Cruz et al. ${ }^{17}$ aimed to identify the prevalence of mosquito allergy and performed SPT with a common mosquito species in Mexico (Aedes aeigypti) in 482 patients ranged in age from 2 to 58 years. Mosquito prick test was positive in 3 out of 12 patients (25\%) with large local reactions, and no significant difference was found between patients 
with or without mosquito allergy. In the childhood study by Manuyakorn et al., ${ }^{10} 34 \%$ of the children were positive to SPT with Culex pipenes, whereas $32 \%$ of the children had positive specific IgE against $A$. communis. In adults with mosquito allergy, the reported prevalence of positive SPT and positive IgE antibodies to various mosquito species is higher compared with children and vary between $46.8-80 \%$ and $45.8-73.8 \%$, respectively. ${ }^{11,14}$ The prevalence of SPT positivity to mosquito allergen was $6.4 \%$ in our cohort, and there was no difference when compared with control group. It seems that an IgE-mediated mosquito allergy is very rare in this population. The sensitivity and specificity of currently available tests in patients with a history of exaggerated or unusual responses to mosquito bites are reported to be limited. ${ }^{2}$

Various researchers have investigated the natural course of reactions after mosquito bites and classified the patients into five stages. ${ }^{18,19}$ Delayed reactions are frequent in children, whereas the prevalence of immediate reactions reported to increase with age during adolescence. ${ }^{20,21}$ In parallel with the previous findings, majority of the children in our cohort were in Stages 2 and 3. ${ }^{10,11}$ Moreover, we found out that the children who develop wheals in a short time after mosquito bites had longer history of symptoms. Erythematous papules were the most frequent lesions in our group. Another interesting finding of our study is the significantly higher prevalence of bullous reactions in children with asthma (41.7\% vs $15.9 \%, \mathrm{P}=0.034)$. Bullous reactions to mosquito bites have been previously reported, ${ }^{22,23}$ however, there is no observed association with an atopic background so far. The exact pathogenesis of the reactions is unknown; however, a hypersensitivity reaction against salivary antigens emerges as a plausible explanation. ${ }^{24}$ Severe skin reactions with various systemic symptoms are encountered in patients with certain conditions such as Epstein-Barr virus (EBV)-associated lymphoproliferative diseases and natural killer cell lymphoproliferative disorders. We consulted the children in our cohort with our Pediatric Hematology Department, and none of the children in the study group had an underlying hematologic disease during our follow-up period. Mosquito bites must be kept in mind in the differential diagnosis of children with bullous reactions, particularly with asthma.

We did not perform specific IgE testing in our patients, nevertheless, performing these in vivo or in vitro tests especially in young children may have little benefit. On the other hand, it was performed in a center which was specialized for children with allergic diseases. The diagnostic procedures and the longitudinal follow-up of the patients were made by pediatric allergy specialists. Our study is one of the few childhood studies that provide unique data about children with unusual or "exaggerated" reactions after mosquito bites. Its prospective and controlled design, along with a fairly large number of participants, are other superiorities.

\section{Conclusion}

In conclusion, our results indicate that the role of commercially available tests in diagnosing children with mosquito hypersensitivity is limited. There is an association between unusual, large, local, or exaggerated reactions after mosquito bites and allergic diseases in children. The severity of reactions increases with age and particularly in children with atopic background.

\section{Conflict of Interest}

The authors declare no potential conflicts of interest with respect to research, authorship, and/or publication of this article.

The authors warrant that the article is original, does not infringe upon any copyright or other proprietary right of any third party, is not under consideration by any other journal, and has not been previously published.

The authors confirm that they have reviewed and approved the final version of the manuscript. The requirements for authorship have been met by each listed author.

We report that there is no potential conflict of interest.

The authors declare that there is no funding for the study.

\section{References}

1. Peng Z, Simons FE. Mosquito allergy: Immune mechanisms and recombinant salivary allergens. Int Arch Allergy Immunol. 2004;133(2):198-209. http://dx.doi.org/10.1159/000076787

2. Crisp HC, Johnson KS. Mosquito allergy. Ann Allergy Asthma Immunol. 2013;110(2):65-9. http://dx.doi.org/10.1016/j.anai. 2012.07.023

3. Peng Z, Simons FE. A prospective study of naturally acquired sensitization and subsequent desensitization to mosquito bites and concurrent antibody responses. J Allergy Clin Immunol. 1998;101(2 Pt 1):284-6. http://dx.doi.org/10.1016/ S0091-6749(98)70395-1

4. Peng Z, Rasic N, Liu Y, Simons FE. Mosquito saliva-specific IgE and IgG antibodies in 1059 blood donors. J Allergy Clin Immunol. 2002;110(5):816-7. http://dx.doi.org/10.1067/mai. 2002.128736

5. Peng Z, Estelle F, Simons R. Mosquito allergy and mosquito salivary allergens. Protein Pept Lett. 2007;14(10):975-81. http://dx.doi.org/10.2174/092986607782541088

6. Global Initiative for Asthma. Global strategy for asthma management and prevention. 2020. Available from: https://www. ginasthma.org (Accessed March 12, 2020).

7. Bousquet J, Khaltaev N, Cruz AA, Denburg J, Fokkens WJ, Togias A, et al. Allergic rhinitis and its impact on asthma (ARIA) 2008 update (in collaboration with the World Health Organization, GA(2)LEN and AllerGen). Allergy. 2008;63 Suppl 86:8-160. http://dx.doi.org/10.1111/j.1398-9995.2007.01620.x

8. Eichenfield LF, Hanifin JM, Luger TA, Stevens SR, Pride HB. Consensus conference on pediatric atopic dermatitis. J Am Acad Dermatol. 2003;49(6):1088-95. https://doi.org/10.1016/ S0190-9622(03)02539-8

9. Sahiner UM, Civelek E, Yavuz ST, Buyuktiryaki AB, Tuncer A, Sekerel BE. Skin prick testing to aeroallergen extracts: What is the optimal panel in children and adolescents in Turkey? Int Arch Allergy Immunol. 2012;157(4):391-8. http://dx.doi. org/10.1159/000329870

10. Manuyakorn W, Itsaradisaikul S, Benjaponpitak S, Kamchaisatian W, Sasisakulporn C, Jotikasthira W, et al. Mosquito allergy in children: clinical features and limitation 
of commercially available diagnostic tests. Asian Pac J Allergy Immunol. 2017;35(4):186-90. http://dx.doi.org/10.12932/AP0842

11. Kulthanan K, Wongkamchai S, Triwongwaranat D. Mosquito allergy: Clinical features and natural course. J Dermatol. 2010;37(12):1025-31. http://dx.doi.org/10.1111/j.1346-8138. 2010.00958.x

12. Tamay Z, Akcay A, Ergin A, Guler N. Prevalence of allergic rhinitis and risk factors in 6- to 7-year-old children in Istanbul, Turkey. Turk J Pediatr. 2014;56(1):31-40. http://dx.doi. org/10.2332/allergolint.13-OA-0661

13. Bolat E, Arikoglu T, Sungur MA, Batmaz SB, Kuyucu S. Prevalence and risk factors for wheezing and allergic diseases in preschool children: A perspective from the Mediterranean coast of Turkey. Allergol Immunopathol (Madr). 2017;45(4):3628. http://dx.doi.org/10.1016/j.aller.2017.01.002

14. Scala E, Pirrotta L, Uasuf CG, Mistrello G, Amato S, Guerra EC, et al. Aedes communis reactivity is associated with bee venom hypersensitivity: $A n$ in vitro and in vivo Study. Int Arch Allergy Immunol. 2018;176(2):101-5. http://dx.doi. org/10.1159/000488866

15. Bemanian MH, Korkinejad NA, Shirkhoda S, Nabavi M, Pourpak Z. Assessment of sensitization to insect aeroallergens among patients with allergic rhinitis in Yazd City, Iran. Iran J Allergy Asthma Immunol. 2012;11(3):253-8.

16. Cantillo JF, Puerta L, Lafosse-Marin S, Subiza JL, Caraballo L, Fernandez-Caldas E. Allergens involved in the cross-reactivity of Aedes aegypti with other arthropods. Ann Allergy Asthma Immunol. 2017;118(6):710-718. http://dx.doi.org/10.1016/j. anai.2017.03.011
17. Gonzalez Diaz SN, Cruz AA, Sedo Mejia GA, Rojas Lozano AA, Valenzuela EA, Vidaurri Ojeda AC. [Prevalence of reactions secundary to mosquito bites Aedes aegypti at en el Regional Center of Allergy and Clinical Immunology, University Hospital, de Monterrey, Nuevo Leon]. Rev Alerg Mex. 2010;57(2):37-43.

18. Mellanby K. Man's reaction to mosquito bites. Nature. 1946;158(4016):554. http://dx.doi.org/10.1038/158554c0

19. McKiel JA, West AS. Nature and causation of insect bite reactions. Pediatr Clin N Am. 1961;8(3):795-816. http://dx.doi. org/10.1016/S0031-3955(16)31157-9

20. Oka K, Ohtaki N. Clinical observations of mosquito bite reactions in man: A survey of the relationship between age and bite reaction. J Dermatol. 1989;16(3):212-9. http://dx.doi. org/10.1111/j.1346-8138.1989.tb01251.x

21. Oka K, Ohtaki N, Igawa K, Yokozeki H. Study on the correlation between age and changes in mosquito bite response. J Dermatol. 2018;45(12):1471-4. http://dx.doi.org/10.1111/ 1346-8138.14688

22. Walker GB, Harrison PV. Seasonal bullous eruption due to mosquitoes. Clin Exp Dermatol. 1985;10(2):127-32. http://dx. doi.org/10.1111/j.1365-2230.1985.tb00540.x

23. Mai S, Mansouri S, Ismaili N, Senouci K. Impressive bullous reaction to mosquito bites. BMJ Case Rep. 2019;12(11): e232791. http://dx.doi.org/10.1136/bcr-2019-232791

24. Penneys NS, Nayar JK, Bernstein H, Knight JW. Circulating antibody detection in human serum to mosquito salivary gland proteins by the avidin-biotin-peroxidase technique. J Am Acad Dermatol. 1988;18(1 Pt 1):87-92. http://dx.doi.org/10.1016/ S0190-9622(88)70013-4 